Scientia Agricola

http://dx.doi.org/10.1590/0103-9016-2015-0076

\title{
Plant proton pumps as markers of biostimulant action
}

\author{
Daniel Basílio Zandonadi ${ }^{*}$, Mirella Pupo Santos², Lisanne Santos Caixeta ${ }^{1}$, Eduardo Barros Marinho ${ }^{1}$, Lázaro Eustáquio Pereira \\ Peres $^{3}$, Arnoldo Rocha Façanha ${ }^{4}$
}

\author{
'Embrapa Vegetables - Lab. of Cell Biology, Rod. BR-060, km \\ 09 - 70359-970 - Brasília, DF - Brazil. \\ Embrapa Cenargen - Lab. of Genetic Transformation - \\ Parque Estação Biológica, Av. W3 Norte - 70770-917 _ \\ Brasília, DF - Brazil. \\ 3University of São Paulo/ESALQ - Lab. of Hormonal Control \\ of Plant Development, C.P. 09 - 13418-900 - Piracicaba, \\ SP - Brazil \\ ${ }^{4}$ State University of North Fluminense - Lab. of Cell and \\ Tissue Biology, Av. Alberto Lamego, n² 2000 - 28016-620 - \\ Campos dos Goytacazes, RJ - Brazil. \\ *Corresponding author <daniel.zandonadi@embrapa.br>
}

Edited by: Paulo Sergio Pavinato

Received March 13, 2015

Accepted May 27, 2015
ABSTRACT: A standard protocol to evaluate the effects of biostimulants on plant physiology is still lacking. The proton pumps present in the vacuolar and plasma membranes are the primary agents responsible for the regulation of the electrochemical gradient that energizes the nutrient uptake system and acid growth mechanism of plant cells. In this study, two of these enzymes were characterized as biochemical markers of biostimulant activity. A simple and fast protocol based on the degree of root acidification using a pH sensitive dye and the Micro-Tom tomato as a plant model is proposed as an efficient methodology to prove the efficacy of biostimulants that are claimed to improve nutrient acquisition and root growth. The results agree with the data from more conventional, expensive and time-consuming proton pump assays. A direct correlation was found between plasmalemma proton-adenosine triphosphatase ( $\mathrm{H}^{+}$-ATPase) activation and the amount of rhizosphere acidification observed in the bromocresol gel. Moreover, roots of the diageotropica (dgt) Micro-Tom plants, defective in auxin responses, barely acidify bromocresol purple gel even in the presence of indole-3-acetic acid (IAA, $1 \mu \mathrm{M})$. The biostimulant TEA (vermicompost water extract, $25 \%$ ) enhances proton extrusion by $40 \%$ in wild type (WT) plants, but no effect was induced in dgt plants. These results reinforce the notion that the class of biostimulant known as humic substances stimulates plant proton pumps and promotes root growth by exerting an auxin-like bioactivity and establish the usefulness of an economically and technically feasible assay to certify this kind of biostimulant.

Keywords: Micro-Tom, acidification, auxin, rhizosphere, bromocresol

\section{Introduction}

Long before the discovery of plant hormone auxin, exogenous organic substances were already described as complementary to mineral nutrients (Bottomley, 1915). The term "auximones" was coined to designate organic extracts from peat able to promote plant growth. A hundred years later, several products have been identified as biostimulants, although still lacking proper scientific evaluation, and only proved to work under controlled conditions (for a review see Calvo et al., 2014).

Although a legal definition for fertilizers and plant protection products exists, an equivalent legislation for plant biostimulants remains to be defined. There are guidelines on efficacy evaluation for the use and registration of these products, but little has been done towards developing a qualitative method for discriminating among the myriad of plant biostimulants increasingly released into the market. How can we certify whether a product is a biostimulant or not? To answer this question and establish a guideline to access biostimulant activities with simple protocols, it is worthwhile using both reproducible plant models and suitable biological markers.

Herein we characterize the efficacy of an easy protocol for screening biostimulant activity. This protocol is based on the 'Micro-Tom' system and proton pump activity, combined as a tool kit. Micro-Tom is a model plant short in both size and life cycle, comparable to Arabidopsis thaliana, with the additional advantage of having significant agronomic relevance (Carvalho et al., 2011). There are several hormone deficient or insensitive mutants available in 'Micro-Tom' (Carvalho et al., 2011), and, therefore, a wide range of processes stimulated by biostimulants can be studied.

Plant hormones can regulate the activity of plant proton pumps (proton-adenosine triphosphatase, $\mathrm{H}^{+}-$ ATPase and vacuolar proton-pyrophosphatase, $\mathrm{H}^{+}$-PPases), eliciting key physiological responses (Marrè and Ballarin-Denti, 1985; Gaxiola et al., 2007). These enzymes are important in plant reactions to environmental challenges. Not surprisingly, humic substances and other kind of biostimulants endowed with hormonal activity have also been found to change the electrochemical gradient of protons formed across the cell membranes via modulation of proton pumps.

This study aimed to: (1) determine whether the bromocresol plate method could be adapted to a routine $\mathrm{H}^{+}$-ATPase assay in order to reduce both time and the economic costs of classical methods; and (2) test 'Micro Tom' as plant model for the study of the auxin-like effects of biostimulants.

\section{Materials and Methods}

The classic biochemical procedure for membrane isolation and $\mathrm{H}^{+}$-ATPase hydrolytic activity was carried out as described in Zandonadi et al., (2010). A simple assay to measure in vivo proton extrusion was performed using the bromocresol purple $\mathrm{pH}$ indicator and potentiometric $\mathrm{pH}$ measurements of a medium containing plants pretreated with IAA as described in Zandonadi et al., (2010), with some modifications due to the Micro-Tom plant model and 
the exposure time of treatments. A vermicompost water extract (TEA) was tested as a biostimulant control. Here we used the reduced auxin sensitive mutant dgt (Kelly and Bradford, 1986; Carvalho et al., 2011) as a negative control. The TEA biostimulant was prepared using a vermicompostto-water ratio of $100 \mathrm{~g}$ of vermicompost to $1 \mathrm{~L}$ of distilled water (TEA $100 \%$ ). This solution remained on a shaker overnight at room temperature to give plenty of time to extract water-soluble humic material. Then, the solution was centrifuged at 3,000g and sterilized by filtration through a sterile filter paper with a pore diameter of $0.22 \mu \mathrm{m}$ under aseptic conditions. The solution was further diluted with distilled water to make TEA (25\%). Vermicompost water extract was used in this concentration because it contains IAA $0.90 \mu \mathrm{M}$ by means of high-performance liquid chromatography (data not shown).

Seeds of the cv. Micro-Tom tomato were surface sterilized with $1 \%(\mathrm{w} / \mathrm{v}) \mathrm{NaClO}$ for $20 \mathrm{~min}$. Afterwards, seeds were washed thoroughly with autoclaved distilled water six times ( 2 min each time) and inoculated into 1 $\%$ agar. Three plates containing three 10-day-old seedlings each were used in each of three independent experiments. Micro-Tom WT (wild type) or dgt (diageotropica) seedlings (primary root $3-4 \mathrm{~cm}$ long) were placed over autoclaved filter paper and treated for 10, 30, 60 and 120 minutes with distilled water (control), IAA $1 \mu \mathrm{M}$ or TEA (25\%) biostimulant (Appendix 1). Subsequently, pre-treated seedlings were transferred to a $5 \mathrm{~mm}$ agar (1 $\%)$ gel layer that contained the $\mathrm{pH}$ bromocresol purple indicator $\left(0.04 \mathrm{~g} \mathrm{dm}^{-3}\right)$ for an additional $24 \mathrm{~h}$ of incubation. The $\mathrm{pH}$ medium was adjusted to $\mathrm{pH} 6.80$ with drops of Tris hydroxymethyl aminomethane (Tris) buffer $100 \mathrm{mM}$ prior to placement of the plants. The $\mathrm{pH}$ was also measured in the gel using a flat $\mathrm{pH}$ probe along the rhizosphere every $12 \mathrm{~mm}$, up to $48 \mathrm{~mm}$ from the primary root, after the $24 \mathrm{~h}$ period of incubation. The specific ATPase activity was secured by using plates with 50-500 $\mu \mathrm{M}$ sodium orthovanadate $\left(\mathrm{Na}_{3} \mathrm{VO}_{4}\right)$, the plasma membrane (PM) $\mathrm{H}^{+}$-ATPase specific inhibitor. For each treatment plate there was one $\mathrm{Na}_{3} \mathrm{VO}_{4}$ control plate.

\section{Results}

Data on humic substance induced $\mathrm{PM} \mathrm{H}^{+}$-ATPase activities were compiled from the available scientific literature (Table 1) in order to create a box and whisker plot, which revealed averages of enzyme stimulation that varied from 28 to $435 \%$ (Figure 1). The PM vesicles isolated from wild type tomato roots treated with IAA $1 \mu \mathrm{M}$, exhibited a stimulation of vanadate-sensitive $\mathrm{H}^{+}$. ATPase activity (Figure 2) as well as rhizospheric acidification (Figure 3). The initial rate of ATP hydrolysis was $40 \%$ higher in WT plants as compared to dgt plants. The enzyme activity was enhanced twofold in WT plants treated with IAA $1 \mu \mathrm{M}$, whilst dgt plants were unaffected. Root acidification in WT plants was $70 \%$ higher than dgt plants (Figure 3). When WT plants were exposed to

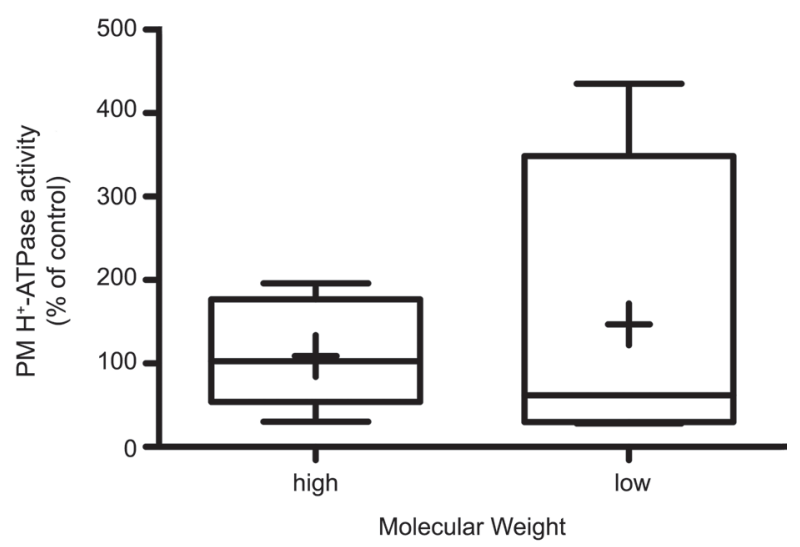

Figure 1 - Box and whisker plot of plasma membrane (PM) protonadenosine triphosphatase ( $\mathrm{H}^{+}-$ATPase) activity of data from Table 1. The horizontal line indicates the median, the plus sign indicates mean, box covers the 25-75\% percentiles and length of each whisker indicates the maximum and minimum values. Left box is from high molecular weight humic substances, and right box is from low molecular weight humic substances.

Table 1 - Plasma membrane proton-adenosine triphosphatase ( $\mathrm{H}^{+}-$ATPase) activity stimulation in vivo or in vitro of plants treated with humic substances isolated from different sources. $\left({ }^{*}\right)$ indicates low molecular weight.

\begin{tabular}{|c|c|c|c|c|}
\hline Source & Treatment & Plant material & Activity (\%) & Reference \\
\hline Sphagnum peat* & $5 \mathrm{~min}$, in vitro & Avena sativa & 35 & Pinton et al., 1992 \\
\hline Lythic rendoll & $20 \mathrm{~min}$, in vivo & A. sativa & 30 & Varanini et al., 1993 \\
\hline Lythic rendoll* & $20 \mathrm{~min}$, in vivo & A. sativa & 435 & Varanini et al., 1993 \\
\hline Sphagnum peat* & $4 \mathrm{~h}$, in vivo & Zea mays & 28 & Pinton et al., 1999 \\
\hline Cambisol * & $16 \mathrm{~h}$, in vivo & Z. mays & 89 & Nardi et al., 2000 \\
\hline Vermicompost & $7 \mathrm{~d}$, in vivo & Z. mays & 66 & Canellas et al., 2002 \\
\hline Vermicompost & $5 \mathrm{~d}$, in vivo & Z. mays & 89 & Zandonadi et al., 2007 \\
\hline Sewage sludge & $5 \mathrm{~d}$, in vivo & Z. mays & 191 & Zandonadi et al., 2007 \\
\hline Ultisol & $5 \mathrm{~d}$, in vivo & Z. mays & 75 & Zandonadi et al., 2007 \\
\hline Incept & $5 \mathrm{~d}$, in vivo & Z. mays & 196 & Zandonadi et al., 2007 \\
\hline Leonardite & $48 \mathrm{~h}$, in vivo & Cucumis sativus & 130 & Elena et al., 2009 \\
\hline Leonardite & $48 \mathrm{~h}$, in vivo & C. sativus & 135 & Mora et al., 2010 \\
\hline Vermicompost & $4 \mathrm{~d}$, in vivo & Z. mays & 50 & Zandonadi et al., 2010 \\
\hline
\end{tabular}




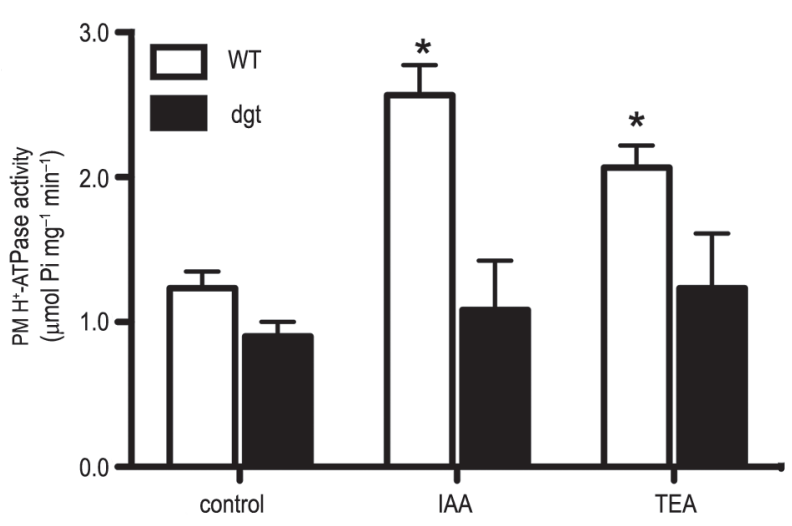

Figure 2 - Hydrolytic plasma membrane (PM) proton-adenosine triphosphatase ( $\mathrm{H}^{+}$-ATPase) activity. Effects of indole-3-acetic acid (IAA) $1 \mu \mathrm{M}$ or TEA $25 \%$ (vermicompost water extract) on initial rate of vanadate-sensitive ATP hydrolysis from Micro-Tom rootderived PM vesicles. Representative experiments of at least two independent membrane preparations from tomato roots. Data represent means \pm standard deviation $(\mathrm{sd})$. Columns designated with stars $\left({ }^{*}\right)$ indicate a significant difference with respect to the control at $p<0.05$ as per Dunnett's test.

auxin, root acidification increased $70 \%$, whilst in auxinexposed dgt plants, $\mathrm{pH}$ was unchanged. Treating WT plants with TEA enhanced proton extrusion by about 40 $\%$, while no effect was found in dgt plants exposed to the same concentration of TEA.

\section{Discussion}

Biostimulants extracted from humus are part of an important group of products encompassing the needs of both industry and farmers (Zandonadi and Busato, 2012). There is a body of evidence of positive effects of these products that are reproduced in laboratory as well as under field conditions (Arancon et al., 2012; Zandonadi et al., 2013; Calvo et al., 2014). Humic substances from vermicompost enhance ATP hydrolysis activity, protein abundance, proton extrusion (Canellas et al., 2002; Zandonadi et al., 2010), and messenger ribonucleic acid (mRNA) levels (Quaggiotti et al., 2004) of the $\mathrm{PM} \mathrm{H}^{+}$ATPases in a way similar to that previously described for the plant hormone, auxin (Frías et al., 1996). These and other studies (reviewed by Zandonadi et al., 2013) have provided compelling evidence to support the original proposition by Façanha et al., (2002) on the potential of the $\mathrm{PM} \mathrm{H}^{+}$-ATPase to be used as a biochemical marker of humus and derived substances endowed with auxin-like activity. The results (Table 1) originated from measurements taken from different plant species, treated with humic substances isolated from various sources, and under different exposure times to the humic substances, varying from $20 \mathrm{~min}$ to 7 days. Nevertheless, even under very different experimental conditions the biostimulants were capable of inducing PM proton pump activity (Fig-
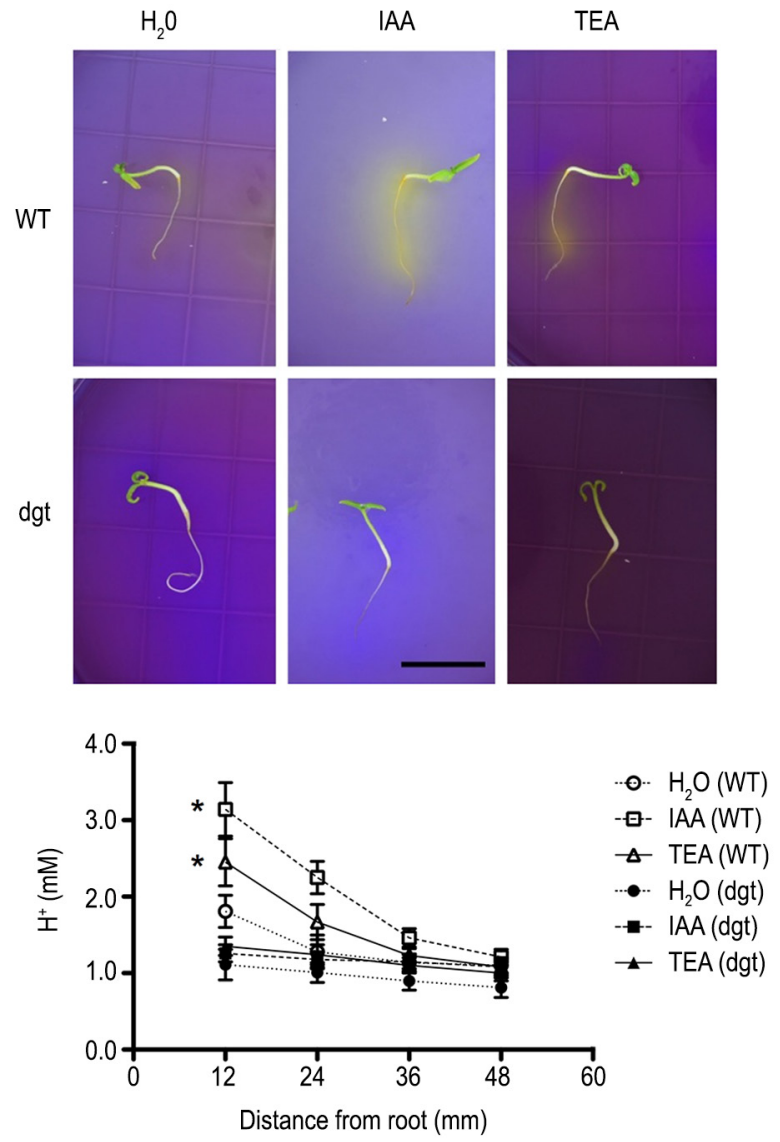

Figure 3 - Rhizospheric pH measurements. Pictures showed root acidification activity of Micro-Tom wild type (WT) or diageotropica (dgt) $10 \mathrm{~d}$ old seedlings treated for $30 \mathrm{~min}$ with water $\left(\mathrm{H}_{2} \mathrm{O}\right)$, indole3-acetic acid (IAA) $1 \mu \mathrm{M}$ or vermicompost water extract (TEA) $25 \%$ and transferred to the agar medium with $\mathrm{pH}$ indicator bromocresol purple for an additional $24 \mathrm{~h}$. The yellow color indicates acidic $\mathrm{pH}$, purple color denotes neutral to alkaline $\mathrm{pH}$. Bar $=2 \mathrm{~cm}$. The graph at the bottom confirmed the proton extrusion viewed in the gel by potentiometric measurements along the rizosphere. Values are means \pm standard deviation ( $s d), n=3$. Results are representative of three independent experiments with 9 plants per treatment. $\left({ }^{*}\right)$ indicates a significant difference with respect to the control at $p<$ 0.05 by Dunnett's test.

ure 1). However, it would be expected that if enzyme activity could be assayed through an easier standardized protocol, data obtained by this process would express a smaller variation and a higher degree of statistical significance.

The $\mathrm{PM} \mathrm{H}^{+}$-ATPase plays a crucial role in nutrient uptake and root growth, which is reflected in its great abundance in root tissues (Palmgren, 2001). Moreover, an optimal metabolic condition for growth and development depends on tightly regulated proton pump activities (Gaxiola et al., 2007). Plasma membrane $\mathrm{H}^{+}$-ATPase acidifies the apoplast which promotes the cell wall loosening required for plant cell growth (Rayle and Cleland, 
1992; Hager, 2003). Protons could act as a coupling factor between the auxin action and the cell wall loosening, resulting in auxin-induced acidification and cell elongation (the acid-growth theory, Rayle and Cleland, 1992; Hager, 2003). In a previous study, we have shown the relationship between root growth and $\mathrm{H}^{+}$-ATPase activation in maize roots treated with humic acids as measured by both classical time-consuming cell fractionation and kinetic enzyme protocols, and a much easier acidification assay (Zandonadi et al., 2010). The protocol for isolation of $\mathrm{H}^{+}$-transport-competent vesicles involves many steps from buffer solution preparation, membrane preparation (including differential and density gradient centrifugations), adenosine triphosphate (ATP) or pyrophosphate (PPi) hydrolysis assays and $\mathrm{H}^{+}$transport assays. This protocol is dependent on the availability of expensive equipment and a quite high level of biochemical expertise for analysis. Depending on the number of treatments, such a method could take up tothree days instead. The bromocresol purple method overcomes most of these restrictions, but fails to provide information about specific biochemical parameters of the proton pumps. On the other hand, it is possible to measure the in vivo vanadate-sensitive acidification of roots in just three hours (an assay in its entirety, from solution preparation to image acquisition).

Using this simple protocol, it was possible to clearly detect that Micro-Tom WT plants had higher proton pumps hydrolytic activity and $\mathrm{H}^{+}$transport in vivo as compared to dgt plants (Figures 2 and 3). It is worth noting that the phenomenon observed is related to preexisting enzymes in the membranes due to the short treatment time $(30 \mathrm{~min})$. Since dgt plants have low auxin sensitivity, it is expected that $\mathrm{H}^{+}$secretion would be reduced in these plants (Coenen et al., 2002). In fact, dgt mutation impairs signaling chains activated by the auxin binding protein 1 (ABP1) receptor, resulting in growth inhibition (Christian et al., 2003). This receptor stimulates $\mathrm{PM} \mathrm{H}^{+}$-ATPase activity, leading to proton extrusion and cell wall loosening. Arabidopsis thaliana aha2 (abbreviated as AHA, for Arabidopsis $\mathrm{H}^{+}$-ATPase) knockdown mutants have impaired lateral root emergence and primary root growth, that result in damaged root architecture (Młodzińska et al., 2014), very similar to dgt plants.

Therefore, exogenous auxins are unable to activate the $\mathrm{PM} \mathrm{H}^{+}$-ATPase activity and proton extrusion in dgt plants (Figures 2 and 3). Biostimulants with auxin-like activity enhances in vivo root acidification in parallel with proton pump activation (Zandonadi et al., 2010). It is tempting to speculate that the $\mathrm{H}^{+}$-PPase activation could be also related to the plant cell proton extrusion shown in the present study, mainly taking into account our previous data, where humic biostimulants were able to induce a concerted activation of the plasmalemma and tonoplast proton pumps (Zandonadi et al., 2007). In line with this notion, plants overexpressing vacuolar $\mathrm{H}^{+}$PPase AVP1 were found to also enhance medium acidification as measured in a bromocresol purple gel (Yang et al., 2014). Efforts should be directed to address this issue in order to understand the role of the $\mathrm{H}^{+}$-PPase on plant root acidification and its relationship with plant biostimulants.

The present proposal to use Micro-Tom mutants, combined with $\mathrm{H}^{+}$-ATPase-derived rhizosphere acidification, as a reference bioassay is mainly focused on biostimulants claimed as root growth promoters. Nevertheless, given the major role of this enzyme (along with the $\mathrm{H}^{+}$-PPase) in so many important physiological processes, further protocols using proton pumps as biochemical markers for other plant tissues and other biostimulant effects, such as stress tolerance, have great potential. Thus, economically and technically feasible protocols like this need to be continuously developed and validated.

Taking together these data also highlight that only when a single plant species, treated under the same conditions, would it be possible to achieve consistent and accurate results to assess the efficacy of different biostimulants. In this context, this study provides scientific validation of an acidification protocol using Micro-Tom mutants that has proved to be a useful tool, and which has the potential to be adopted by the plant product sector, biostimulant councils and government agriculture departments as a quick and easy reference bioassay.

\section{Conclusions}

Micro-Tom mutants and $\mathrm{H}^{+}$-ATPase-derived rhizosphere acidification could be used as an easy bioassay for checking for biostimulants that stimulate root growth. It is important to have a reference protocol with both a standard plant and period of treatment to identify whether a biostimulant is efficient or not and could replicate consistent results under field condition as a second step. The standard protocol for biostimulants claimed as root growth promoters should be both technically accessible and economically viable. This is the case of the rhizosphere acidification assay using Micro-Tom plants with hormone deficiency or insensitivity.

\section{Acknowledgements}

We gratefully acknowledge Dr. Richard Lamar for revision and helpful discussion of the manuscript and the Brazilian National Council for Scientific and Technological Development (CNPq) for financial support.

\section{References}

Arancon, N.Q.; Pant, A.; Radovich, T.; Hue, N.V.; Potter, J.K.; Converse, C.E. 2012. Seed germination and seedling growth of tomato and lettuce as affected by vermicompost water extracts (Teas). HortScience 47: 1722-1728.

Bottomley, W.B. 1915. A bacterial test for plant food accessories: (auximones). Proceedings of the Royal Society of London. Series B. Containing Papers of a Biological Character 89: 102-108. 
Calvo, P.; Nelson, L.; Kloepper, J.W. 2014. Agricultural uses of plant biostimulants. Plant and Soil 383: 3-14.

Canellas, L.P.; Olivares, F.L.; Okorokova-Façanha, A.L.; Façanha, A.R. 2002. Humic acids isolated from earthworm compost enhance root elongation, lateral root emergence, and plasma membrane $\mathrm{H}^{+}$-ATPase activity in maize roots. Plant Physiology 130: 1951-1957.

Carvalho, R.F.; Campos, M.L.; Pino, L.E.; Crestana, S.L.; Zsögön, A.; Lima, J.E.; Benedito, V.A.; Peres, L.E. 2011. Convergence of developmental mutants into a single tomato model system: 'Micro-Tom' as an effective toolkit for plant development research. Plant Methods 7: 1-14.

Christian, M.; Steffens, B.; Schenck, D.; Lüthen, H. 2003. The diageotropica mutation of tomato disrupts a signaling chain using extracellular auxin binding protein 1 as a receptor. Planta 218: 309-314.

Coenen, C.; Bierfreund, N.; Lüthen, H.; Neuhaus, G. 2002. Developmental regulation of $\mathrm{H}^{+}$-ATPase-dependent auxin responses in the diageotropica mutant of tomato (Lycopersicon esculentum). Physiologia Plantarum 114: 461471.

Façanha, A.R.; Façanha, A.L.O.; Olivares, F.L.; Guridi, F.; Santos, G.D.A.; Velloso, A.C.X.; Rumjanek, V.M.; Brasil, F.; Schripsema, J.; Braz-Filho, R.; Oliveira, M.A.; Canellas, L.P. 2002. Humic acids bioactivity: effects on root development and on the plasma membrane proton pump. Pesquisa Agropecuária Brasileira 37: 1301-1310 (in Portuguese, with abstract in English).

Frías, I.; Caldeira, M.T.; Pérez-Castiñeira, J.R.; Navarro-Aviñó, J.P.; Culiañez-Maciá, F.A.; Kuppinger, O.; Serrano, R. 1996. A major isoform of the maize plasma membrane $\mathrm{H}\left({ }^{+}\right)$-ATPase: characterization and induction by auxin in coleoptiles. The Plant Cell 8: 1533-1544.

Gaxiola, R.A.; Palmgren, M.G.; Schumacher, K. 2007. Plant proton pumps. FEBS Letters 581: 2204-2214.

Hager, A. 2003. Role of the plasma membrane $\mathrm{H}^{+}$-ATPase in auxin-induced elongation growth: historical and new aspects. Journal of plant research 116: 483-505.

Kelly, M.O.; Bradford, K.J. 1986. Insensitivity of the diageotropica tomato mutant to auxin. Plant Physiology 82: 713-717.

Marrè, E.; Ballarin-Denti, A. 1985. The proton pumps of the plasmalemma and the tonoplast of higher plants. Journal of Bioenergetics and Biomembranes 17: 1-21.

Młodzińska, E.; Kłobus, G.; Christensen, M.D.; Fuglsang, A.T. 2014. The plasma membrane $\mathrm{H}^{+}$-ATPase AHA2 contributes to the root architecture in response to different nitrogen supply. Physiologia Plantarum 154: 270-282.

Palmgren, M.G. 2001. Plant plasma membrane $\mathrm{H}^{+}$-ATPases: powerhouses for nutrient uptake. Annual Review of Plant Biology 52: 817-845.

Quaggiotti, S.; Ruperti, B.; Pizzeghello, D.; Francioso, O.; Tugnoli, V.; Nardi, S. 2004. Effect of low molecular size humic substances on nitrate uptake and expression of genes involved in nitrate transport in maize (Zea mays L.). Journal of Experimental Botany 55: 803-813.
Rayle, D.L.; Cleland, R.E. 1992. The acid growth theory of auxininduced cell elongation is alive and well. Plant physiology 99: 1271-1274.

Yang, H.; Zhang, X.; Gaxiola, R.A.; Xu, G.; Peer, W.A.; Murphy, A.S. 2014. Over-expression of the Arabidopsis protonpyrophosphatase AVP1 enhances transplant survival, root mass, and fruit development under limiting phosphorus conditions. Journal of Experimental Botany 149: 3-9.

Zandonadi, D.B.; Busato, J.G. 2012. Vermicompost humic substances: technology for converting pollution into plant growth regulators. International Journal of Environmental Science and Engineering Research 3: 73-84.

Zandonadi, D.B.; Canellas, L.P.; Façanha, A.R. 2007. Indolacetic and humic acids induce lateral root development through a concerted plasmalemma and tonoplast $\mathrm{H}^{+}$pumps activation. Planta 225: 1583-1595.

Zandonadi, D.B.; Santos, M.P.; Busato, J.G.; Peres, L.E.P.; Façanha, A.R. 2013. Plant physiology as affected by humified organic matter. Theoretical and Experimental Plant Physiology 25: 13-25.

Zandonadi, D.B.; Santos, M.P.; Dobbss, L.B.; Olivares, F.L.; Canellas, L.P.; Binzel, M.L.; Façanha, A.R. 2010. Nitric oxide mediates humic acids-induced root development and plasma membrane $\mathrm{H}^{+}$-ATPase activation. Planta 231: 1025-1036.

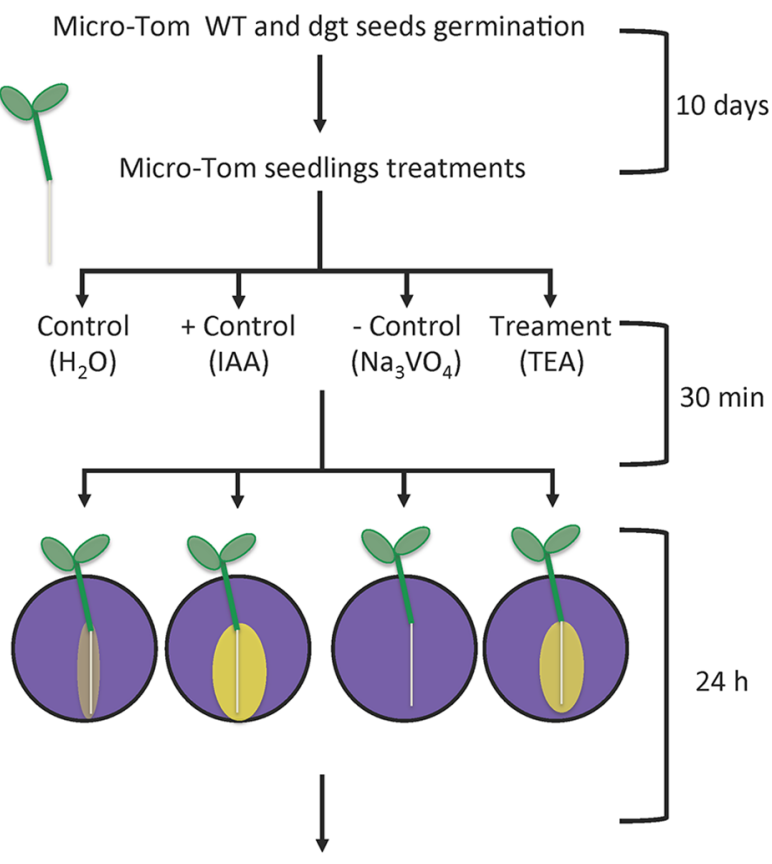

$\mathrm{pH}$ measurements

Image acquisition

Appendix 1 - Scheme of the procedure of rhizospheric $\mathrm{pH}$ measurements. $W T=$ Wild Type; dgt = diageotropica; IAA = indole3-acetic acid; $\mathrm{Na}_{3} \mathrm{VO}_{4}=$ orthovanadate; TEA = vermicompost water extract. 